\title{
DYNAMICS OF THE DISTRIBUTION MECHANISM WITH ROCKING TAPPET WITH ROLL
}

\author{
Florian Ion Tiberiu Petrescu \\ Bucharest Polytechnic University, Romania \\ E-mail: petrescuflorian@yahoo.com \\ Relly Victoria Virgil Petrescu \\ Bucharest Polytechnic University, Romania \\ E-mail: petrescuvictoria@yahoo.com
}

Submission: 01/09/2015

Revision: 18/09/2015

Accept: 21/11/2018

\section{ABSTRACT}

In this paper the authors present shortly an original method to make the dynamic synthesis of a mechanism with rotary cam and rotated tappet with roll, used with priority at the distribution mechanisms from the heat engines with internal combustion. This type of distribution can improve the changes of gases, and may decrease significantly the level of vibration, noises, and emissions. As long as electricity and heat are produced by burning fossil fuels is pointless to try to replace all thermal engines with electric motors, as loss of energy and pollution will be even larger. However, it is well to continuously improve the thermal engines, to reduce thus fuel consumption. At the heat engine with internal combustion a great loss of power is realized and by the distribution mechanism, reason for the improvement of the functionality of this mechanism. The dynamic synthesis of this type of distribution mechanism can be made shortly, by the Cartesian coordinates, but to determine these coordinates some trigonometric parameters of the mechanism are necessary. Dynamics and forces of this distribution mechanism are presented as well. The dynamic coefficient $D$ is also introduced. 
Keywords: Distribution mechanism, Rotary cam, Rotating tappet with roll, Cam dynamics, Cam dynamic synthesis, Forces, Velocities, Powers, Efficiency, Dynamic coefficient

\section{INTRODUCTION}

Mechanisms with rotary cam and rotating tappet with roller (Module F) are presented, as it is shown in Figure 1. They have a unique kinematic and dynamic due primarily of the mechanism geometry, which forces to study them in greater detail if need to determine the kinematic and dynamic precision of these mechanisms. Typically the study of this type of mechanism is made approximately, considering being enough for both, kinematic and dynamic to study the center of the coupling $B$ (the center of the roll). This approximation has a great weakness, because it neglects dynamic kinematics, the forces transmission, and precision of the mechanism, which leads to a dynamic study inadequate.

In this paper the authors present shortly an original trigonometric method to make the dynamic synthesis of a mechanism with rotary cam and rotated tappet with roll, used with priority at the distribution mechanisms from the heat engines with internal combustion.

This type of distribution can improve the changes of gases, and may decrease significantly the level of vibration, noises, and emissions.

As long as produce electricity and heat by burning fossil fuels is pointless to try to replace all thermal engines with electric motors, as loss of energy and pollution will be even larger. However, it is well to continuously improve the thermal engines, to reduce thus fuel consumption.

At the heat engine with internal combustion a great loss of power is realized and by the distribution mechanism, and for that reason needs to improve the functionality of this mechanism.

The synthesis of this type of distribution mechanism can be made shortly, by the Cartesian coordinates, but to determine these coordinates some trigonometric parameters of the mechanism are necessary as well.

Why to study today this type of mechanism? The first human revolution was produced by the mechanisms with cams used in the automatic looms introduced in 
England in 1719 by John Kay. The second human revolution was produced in 1866 when the German engineer Nikolaus August Otto has invented his engine in four times with gas, a heat engine with internal combustion with distribution having all valves in the known today form of mushrooms. Cam mechanisms can transmit high forces and loads with a high reliability and dynamic. For this reason they are irreplaceable in various fields in which they are used. Distribution mechanisms with cam, follower and valve are irreplaceable in internal combustion engines.

This work study the dynamics of the distribution mechanism module $F$, with rotation cam and rotating tappet with roll Figure 1.

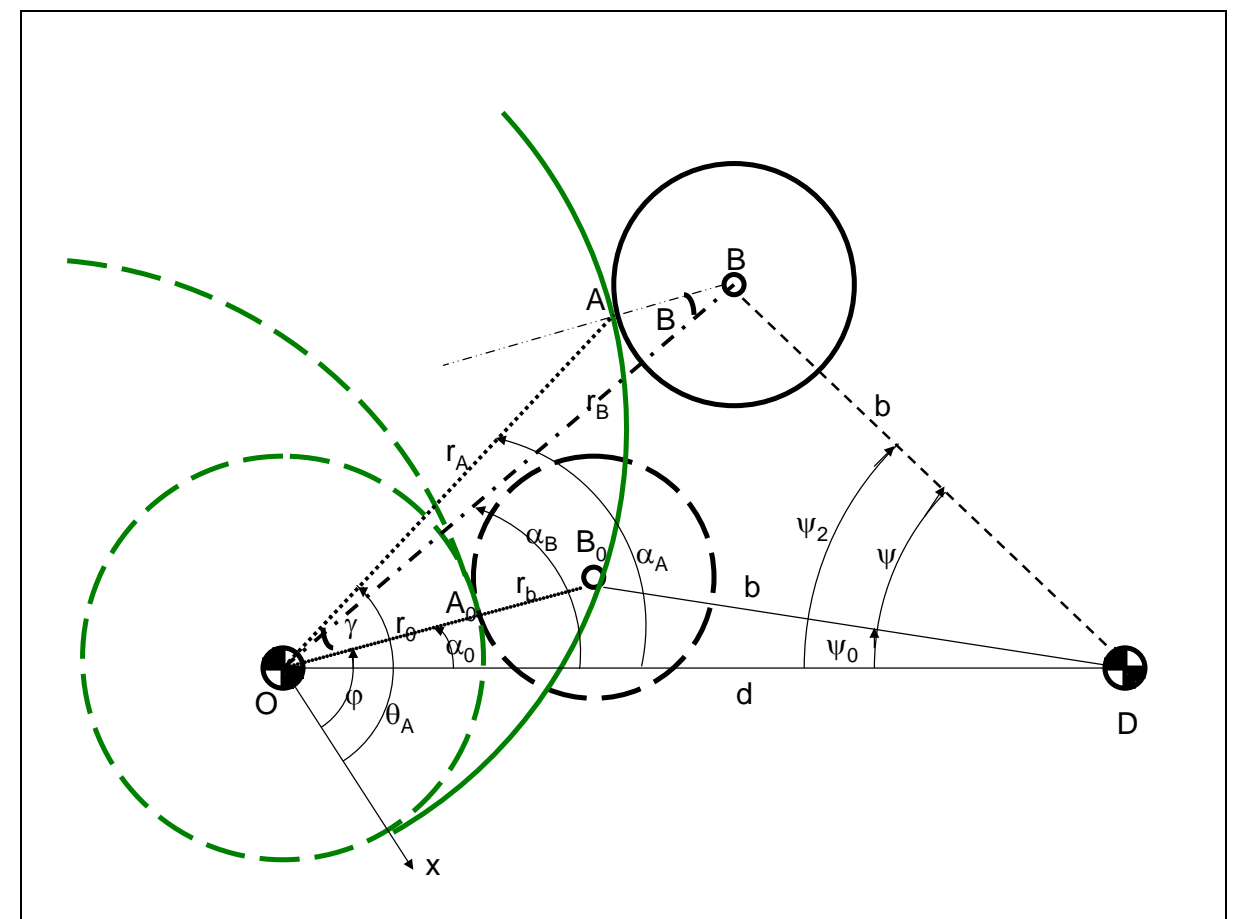

Figure 1: Mechanism with rotating cam and rotating tappet with roll

Internal combustion engines in four-stroke (Otto, Diesel) are robust, dynamic, compact, powerful, reliable, economic, autonomous, independent and will be increasingly clean (WANG, 2011).

Magnetic motors (combined with the electromagnetic) are just in the beginning, but they offer us a good perspective, especially in the aeronautics industry.

The Otto engines or those with internal combustion in general, will have to adapt and to hydrogen fuel.

In some countries (USA, Brazil, Germany) producing alcohol or vegetable oils, for their use as fuel (KARIKALAN, 2013). 
INDEPENDENT JOURNAL OF MANAGEMENT \& PRODUCTION (IJM\&P)

http://www.ijmp.jor.br

v. 10, n. 3, May - June 2019

ISSN: 2236-269X

DOI: 10.14807/ijmp.v10i3.367

In the future, aircraft will use ion engines, magnetic, laser or various micro particles accelerated. Now, and the life of the jet engine begin to end.

Recently it was announced that occurred in Germany car that runs on salt water. This means that we will not put in tank oil or water but salt water.

If Otto engine production would stop right now, they will still working until at least about 40-50 years to complete replacement of the existing fleet today.

In full energy crisis since 1970 until today, production and sale of cars equipped with internal combustion heat engines has skyrocketed, from some millions yearly to over sixty millions yearly now, and the world fleet started from tens of millions reached today the billion. As long as we produce electricity and heat by burning fossil fuels is pointless to try to replace all thermal engines with electric motors, as loss of energy and pollution will be even larger.

However, it is well to continuously improve the thermal engines, to reduce thus fuel consumption. Planet supports now about one billion motor vehicles in circulation. Even if we stop totally production of heat engines, would still need minimum 50 years to eliminate total the existing car park in the current rate.

\section{FORCES, VELOCITIES, POWERS, EFFICIENCY OF MECHANISM}

Speeds and forces transmitted by the mechanism can be watched in Figure 2.

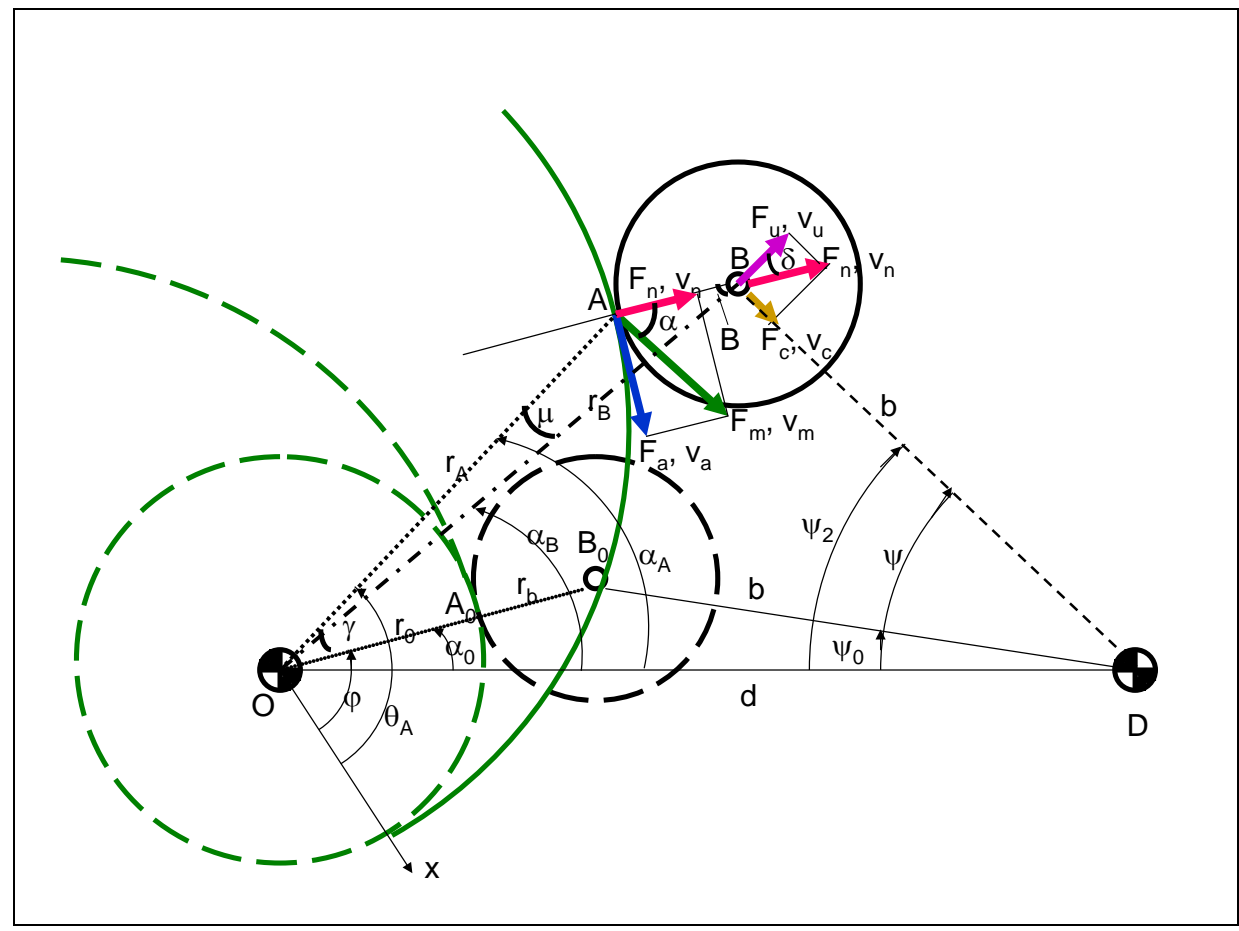

Figure 2: Forces and velocities of the mechanism 
Forces and speeds (relations of the system 1).

$$
\left\{\begin{array}{l}
F_{a}=F_{m} \cdot \sin \alpha \\
v_{a}=v_{m} \cdot \sin \alpha \\
F_{n}=F_{m} \cdot \cos \alpha \\
v_{n}=v_{m} \cdot \cos \alpha \\
F_{c}=F_{n} \cdot \sin \delta \\
v_{c}=v_{n} \cdot \sin \delta \\
F_{u}=F_{n} \cdot \cos \delta=F_{m} \cdot \cos \alpha \cdot \cos \delta \\
v_{u}=v_{n} \cdot \cos \delta=v_{m} \cdot \cos \alpha \cdot \cos \delta \\
P_{u}=F_{u} \cdot v_{2}=F_{m} \cdot v_{m} \cdot \cos 2 \alpha \cdot \cos ^{2} \delta \\
P_{c}=F_{m} \cdot v_{m}
\end{array}\right.
$$

Where $F_{M}$ and $V_{m}$ mean the force of entry (input force) and entry velocity (input velocity); both perpendicular to OA in A (green color on the Figure 2).

Force $F_{m}$ can be broken down into two components: $F_{a}$ (blue) and $F_{n}$ (red); (The velocity $\mathrm{Vm}$ as well).

Component $\mathrm{F}_{\mathrm{a}}$ is a force to slip between elements tangential to the two profiles contact in point $A$, it produces slippage between the two profiles (the cam and roller tappet). This component gives a moment to roll center $B\left(M=F_{a} . r_{b}\right)$, moment which can produce the rolling of roll (This is advantageous because it always changes the focal point of the roll, which is thus reduced wear and uniformity throughout the surface of the roller).

Component $F_{n}$ is the main one, which is transmitted to the roller and then to the tappet. It is perpendicular to $F_{a}$ and tangent to the right $n-n$ passing through the points $A$ and $B$. When the follower rises (as shown in figure 2) force $F_{n}$ presses the roller, so it is directed from $A$ to $B$. 
Force $F_{n}(r e d)$ shall be forwarded radial to the center roll where can be broken down into two components, in two directions: one direction is along tappet from $\mathrm{B}$ to $\mathrm{D}$, and the other direction is perpendicular on the pushrod (DB) in $\mathrm{B}$.

Component $\mathrm{F}_{\mathrm{c}}$ (mustard color) presses the follower along it, thus compressing it, and component $F_{u}$ (mauve color) perpendicular in $\mathrm{B}$ on DB, produces tappet rotation around tappet pivot $\mathrm{D}$, as it is up to the single part useful.

All speeds decompose like forces.

Relations linking forces and those of speeds are given in the system (1). As can be seen there are two angles of pressure, $\alpha$ and $\delta$.

Instantaneous yield mechanism (see the relationship 2), is the ratio between utile (output) power and consumption (input) power, so using the last two relations of the system (1) we obtain the expression instantly mechanical efficiency of the mechanism (2).

$$
\left\{\begin{array}{l}
\cos \alpha \cdot \cos \delta=\frac{\psi^{\prime} \cdot b}{r_{A}} \cdot \cos ^{2} \delta \\
\eta_{i}=\frac{P_{u}}{P_{c}}=\cos ^{2} \alpha \cdot \cos ^{2} \delta=(\cos \alpha \cdot \cos \delta)^{2}=\left(\frac{\psi^{\prime} \cdot b}{r_{A}} \cdot \cos ^{2} \delta\right)^{2}=\frac{\psi^{\prime 2} \cdot b^{2}}{r_{A}^{2}} \cdot \cos ^{4} \delta \\
\eta_{i}=\frac{P_{u}}{P_{c}}=\cos ^{2} \alpha \cdot \cos ^{2} \delta=(\cos \alpha \cdot \cos \delta)^{2}=\frac{\psi^{\prime 2} \cdot b^{2}}{r_{A}^{2}} \cdot \cos ^{4} \delta
\end{array}\right.
$$

Instantly mechanical efficiency is the square of the product of the cosines of the two pressure angles $\alpha$ and $\delta$, or is the fourth power of the pressure $\delta$ angle amplified with a variable, $\frac{\psi^{\prime 2} \cdot b^{2}}{r_{A}^{2}}$.

\section{DETERMINATION OF THE TRANSFER FUNCTION OF THE MOVEMENT}

Next is determined the function of motion transmitting (the transmissivity function or coefficient) to the rotating cam mechanism and rotating follower with roller (F module), function denoted by D (PETRESCU, 2013).

Between helpful velocity $\left(\mathrm{v}_{\mathrm{u}}\right)$ and known velocity $\left(\mathrm{v}_{2}\right)$ of the tappet occurs a difference, which must be embedded in the transmission coefficient $D$, or the transmission function D (PETRESCU, 2015a).

Write the tappet reduced velocity vB2r in the form known (3). 


$$
v_{B 2 r}=\frac{v_{B 2}}{\omega}=b \cdot \psi^{\prime}
$$

Absolute speed tappet in B (relation 4) is obtained by multiplying the reduced speed (3) with $\omega$.

$$
v_{B 2}=b \cdot \psi^{\prime} \cdot \omega
$$

See this velocity in its dynamic form (actual 5), together with an inserted coefficient of motion transmission, D:

$$
v_{2}=b \cdot \psi^{\prime} \cdot D \cdot \omega
$$

Useful speed obtained from system 1 (and figure 2) may be writhed in the form 6.

$\left\{\begin{array}{l}v_{m}=r_{A} \cdot \otimes_{A}^{\&}=r_{A} \cdot \theta_{A}^{\prime} \cdot \omega \text { dynamic obtained } \\ v_{u}=v_{m} \cdot \cos \alpha \cdot \cos \delta=v_{m} \cdot \frac{b \cdot \psi^{\prime}}{r_{A}} \cdot \cos ^{2} \delta=\theta_{A}^{\prime} \cdot \omega \cdot b \cdot \psi^{\prime} \cdot \cos ^{2} \delta=b \cdot \psi^{\prime} \cdot \theta_{A}^{\prime} \cdot \cos ^{2} \delta \cdot \omega\end{array}\right.$

Two speeds (5-6) equaling gets the expression of transmission (dynamic) coefficient D (relation 7).

$$
D=\theta_{A}^{\prime} \cdot \cos ^{2} \delta
$$

Considering classical variant (without dynamic input), when $v_{m}=r_{A} \cdot \omega$, the dynamic coefficient $D$ takes the simplified value (8).

$$
D=\cos ^{2} \delta
$$

\section{DYNAMICS OF MODULE F}

For the dynamic calculations one uses the below original relations (9-11) obtained by a double integration of the Newton equation (PETRESCU, 2014).

$$
\begin{aligned}
& \Delta X=-\frac{\frac{k^{2}+2 k K}{(K+k)^{2}} \cdot s^{2}+\frac{2 k x_{0}}{K+k} \cdot s+\frac{\left[\frac{K^{2}}{(K+k)^{2}} \cdot m_{S}^{*}+m_{T}^{*}\right] \cdot \omega^{2}}{K+k} \cdot y^{\prime 2}}{2 \cdot\left[s+\frac{k x_{0}}{K+k}\right]} \\
& \Delta X=-\frac{\frac{k^{2}+2 k K}{(K+k)^{2}} \cdot s^{2}+\frac{2 k x_{0}}{K+k} \cdot s+\frac{\left[\frac{K^{2}}{(K+k)^{2}} \cdot m_{S}^{*}+m_{T}^{*}\right] \cdot \omega^{2}}{K+k} \cdot\left(D \cdot s^{\prime}\right)^{2}}{2 \cdot\left[s+\frac{k x_{0}}{K+k}\right]}
\end{aligned}
$$

Determining $\Delta \mathrm{X}$ it can calculating then $\mathrm{X}$ with expression (11).

$$
X=s+\Delta X
$$


INDEPENDENT JOURNAL OF MANAGEMENT \& PRODUCTION (IJM\&P)

http://www.ijmp.jor.br

v. 10, n. 3, May - June 2019

ISSN: 2236-269X

DOI: 10.14807/ijmp.v10i3.367

Where $s$ is the theoretical tappet movement law and $\mathrm{x}$ is the real (dynamic) tappet movement law; $\mathrm{K}$ is the elastic constant of the system and $\mathrm{k}$ is the elastic constant of the valve spring; $x_{0}$ is the valve spring pretension; $m_{S}^{*}$ is the valve mass reduced at the valve axis; $m_{T}^{*}$ is the tappet mass reduced at the valve axis.

Then changing the rotation moving of the tappet into a translation moving of the valve (see the Figure 3, and relations 12-13).

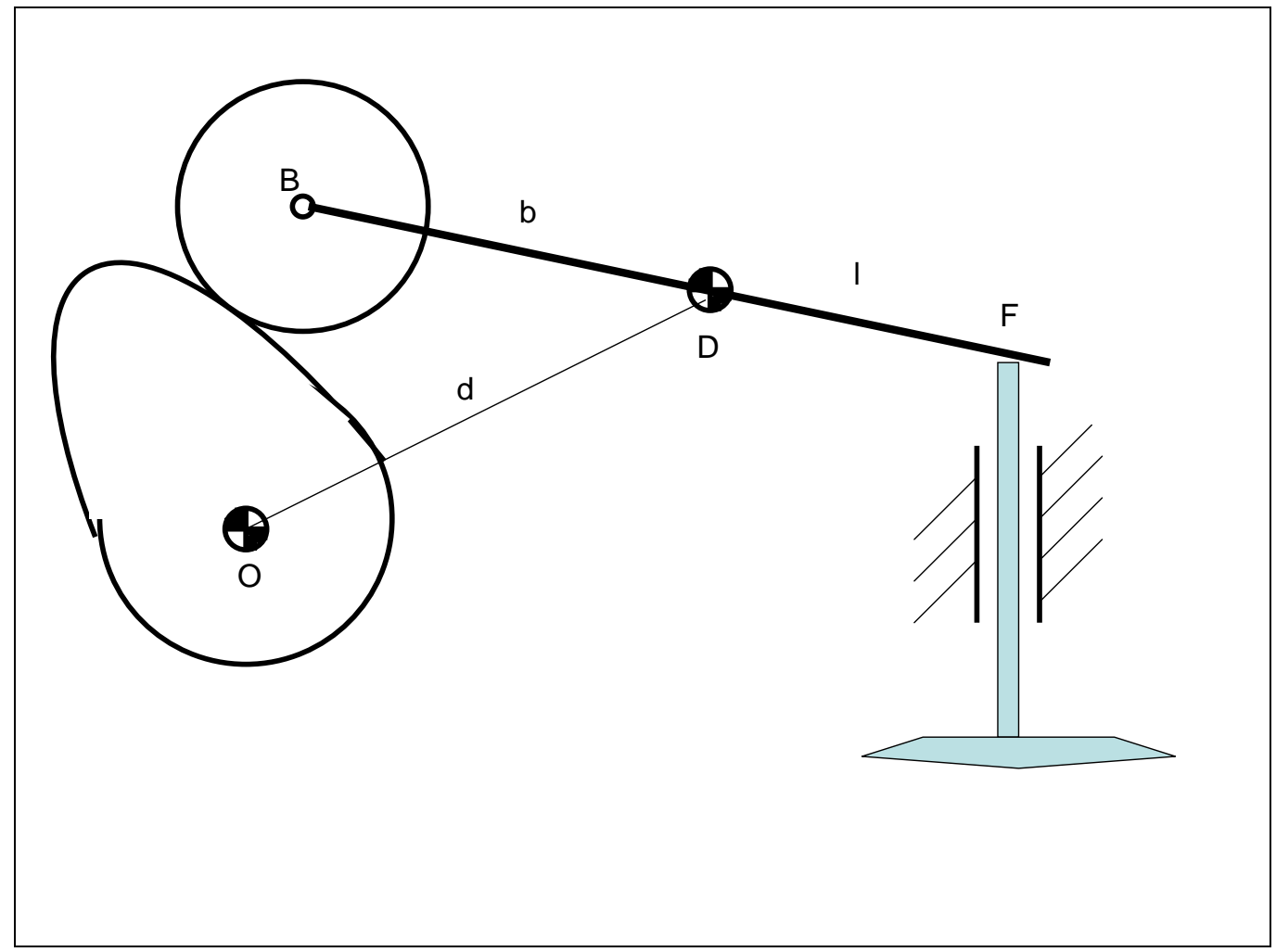

Figure 3: Converting the rotation moving of the tappet into a translation moving of the valve. Simplified diagram.

$l=\frac{b}{i}$

$$
\left\{\begin{array}{l}
s=\frac{b}{i} \cdot \psi \\
s^{\prime}=\frac{b}{i} \cdot \psi^{\prime} \\
s^{\prime \prime}=\frac{b}{i} \cdot \psi^{\prime \prime} \\
s^{\prime \prime}=\frac{b}{i} \cdot \psi^{\prime \prime}
\end{array}\right.
$$


INDEPENDENT JOURNAL OF MANAGEMENT \& PRODUCTION (IJM\&P)

http://www.ijmp.jor.br

v. 10, n. 3, May - June 2019

ISSN: 2236-269X

DOI: 10.14807/ijmp.v10i3.367

\section{DYNAMIC ANALYSIS OF THE MODULE F}

The dynamic analysis begins with the classical law sine (see diagram of the figure 4 , and the profile of the figure 5), to can be compared with the known law dynamic module C classic (AMORESANO, 2013; PETRESCU, 2015b).

It uses a drive shaft rotation speed of $n=5500$ [ $\mathrm{r} / \mathrm{min}$ ], the theoretical maximum displacement both the valve and the tappet, $\mathrm{h}=10[\mathrm{~mm}](\mathrm{CHOI}, 1994)$.

The phase angle is $\varphi_{u}=\varphi_{c}=60$ [degree]; core radius has value $r_{0}=24[\mathrm{~mm}]$. Roll radius has been adopted the value $r_{b}=20[\mathrm{~mm}] ; b=20[\mathrm{~mm}] ; d=50[\mathrm{~mm}]$.

Valve spring adjustments are: $k=60[\mathrm{~N} / \mathrm{mm}]$ şi $\mathrm{x}_{0}=30[\mathrm{~mm}]$.

The yield has a high value, $\eta=12.0 \%$.

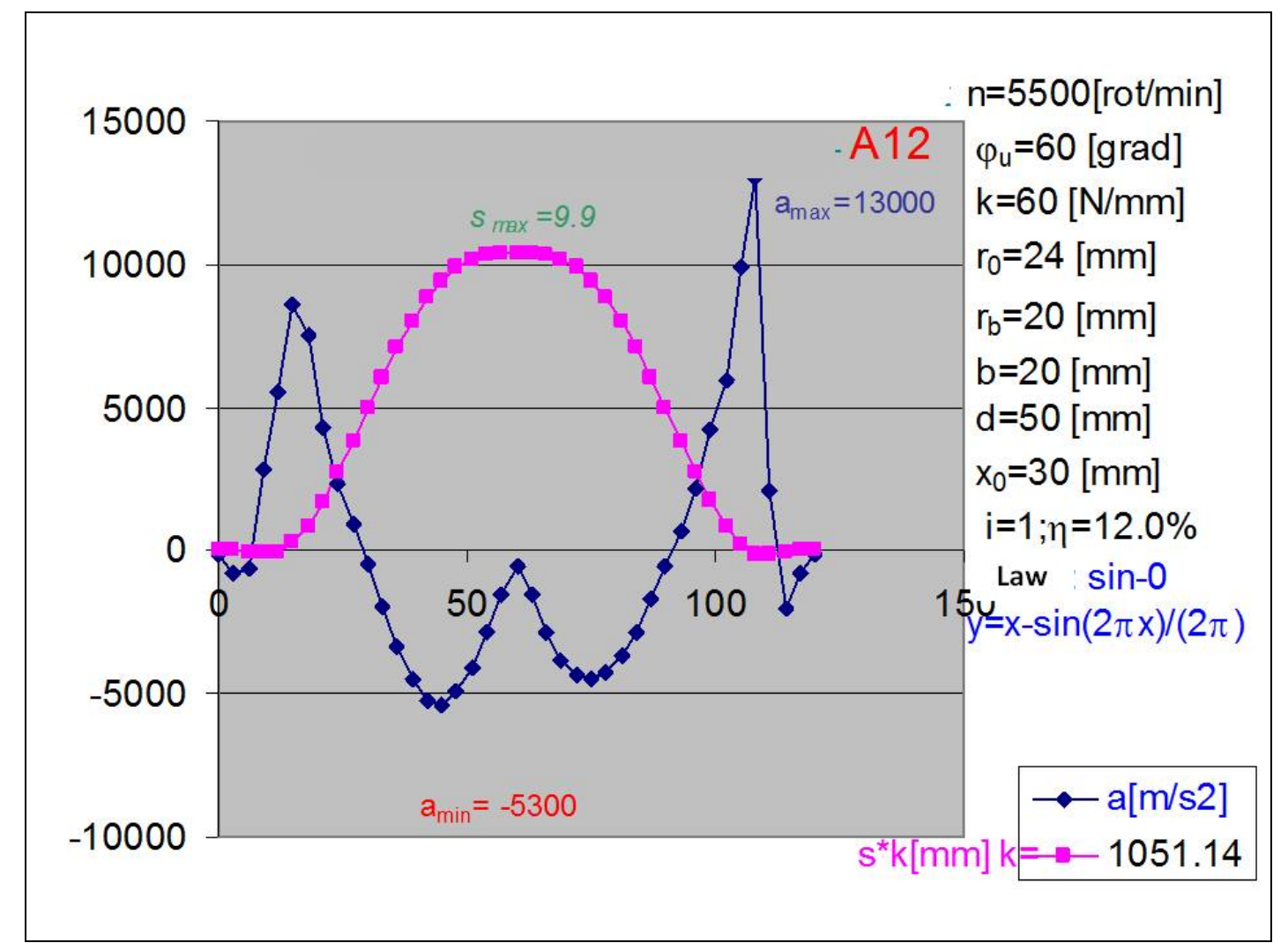

Figure 4: Dynamic analysis of the module F. Law Sine, $\mathrm{n}=5500$ [rot $/ \mathrm{min}], \varphi_{\mathrm{u}}=60$ [deg], $\mathrm{r}_{0}=24[\mathrm{~mm}], \mathrm{r}_{\mathrm{b}}=20[\mathrm{~mm}]$.

Dynamic is better (in general) compared with that of the module classic, C, in conditions in that the real movement of the valve, $s$, almost doubled! 


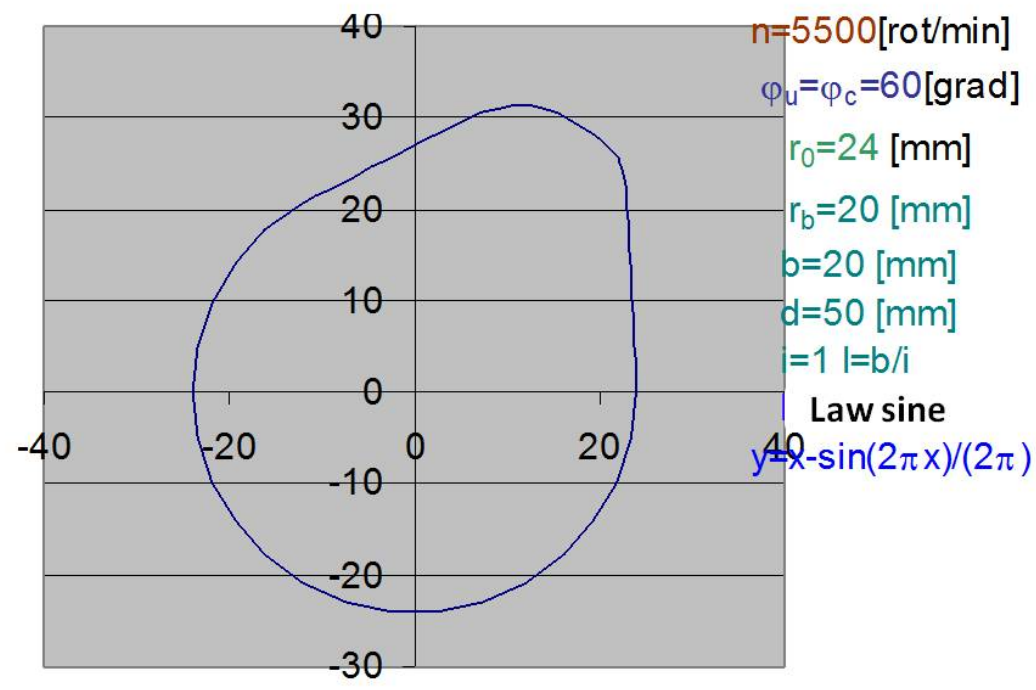

Figure 5: Cam profile of the module F. Law Sine, $\varphi \mathrm{u}=60$ [deg], $r_{0}=24[\mathrm{~mm}], \mathrm{r}_{b}=20$ $[\mathrm{mm}]$.

For the law cosine lifting is higher as compared with the law sine. See the Figure 6-7.

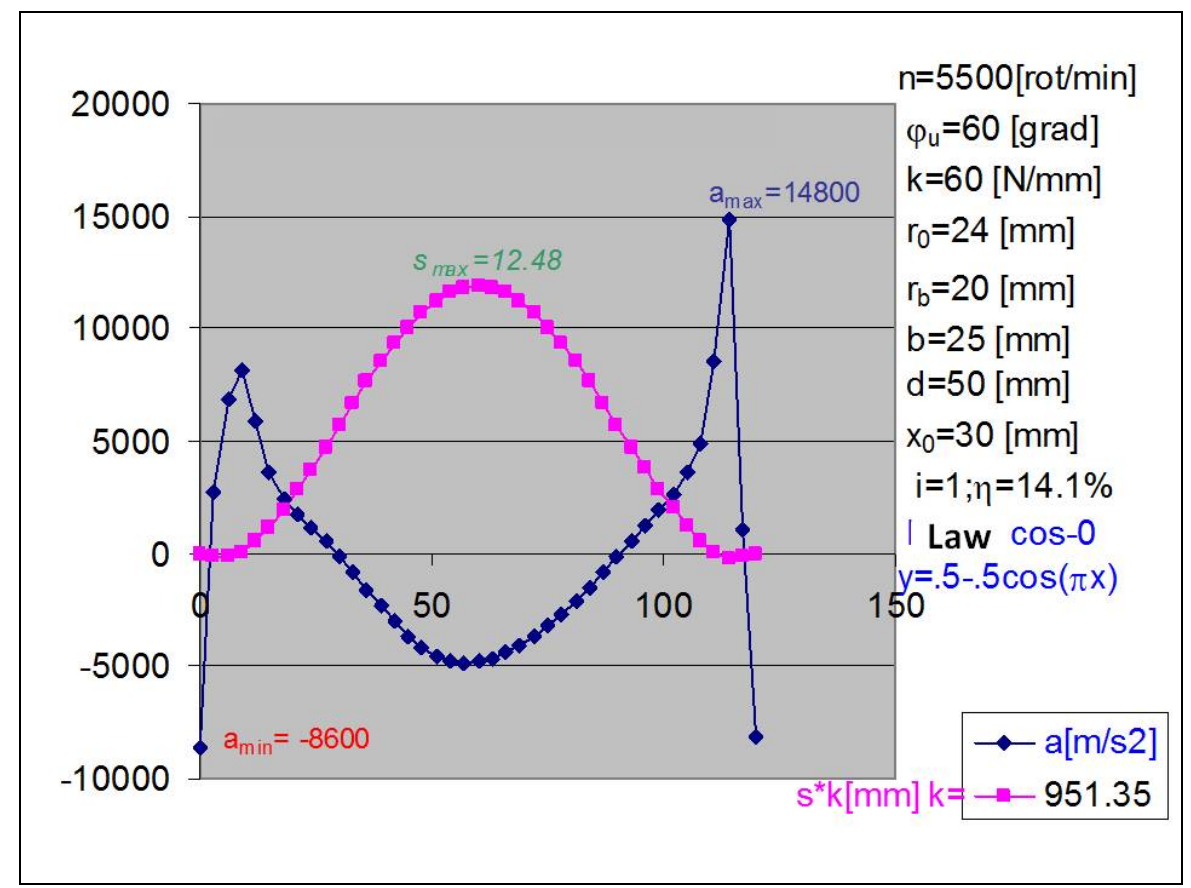

Figure 6: Dynamic analysis of the module F. Law Cosine, $\mathrm{n}=5500$ [rot $/ \mathrm{min}], \varphi \mathrm{u}=60$ [deg], $r_{0}=24[\mathrm{~mm}], \mathrm{r}_{b}=20[\mathrm{~mm}]$. 


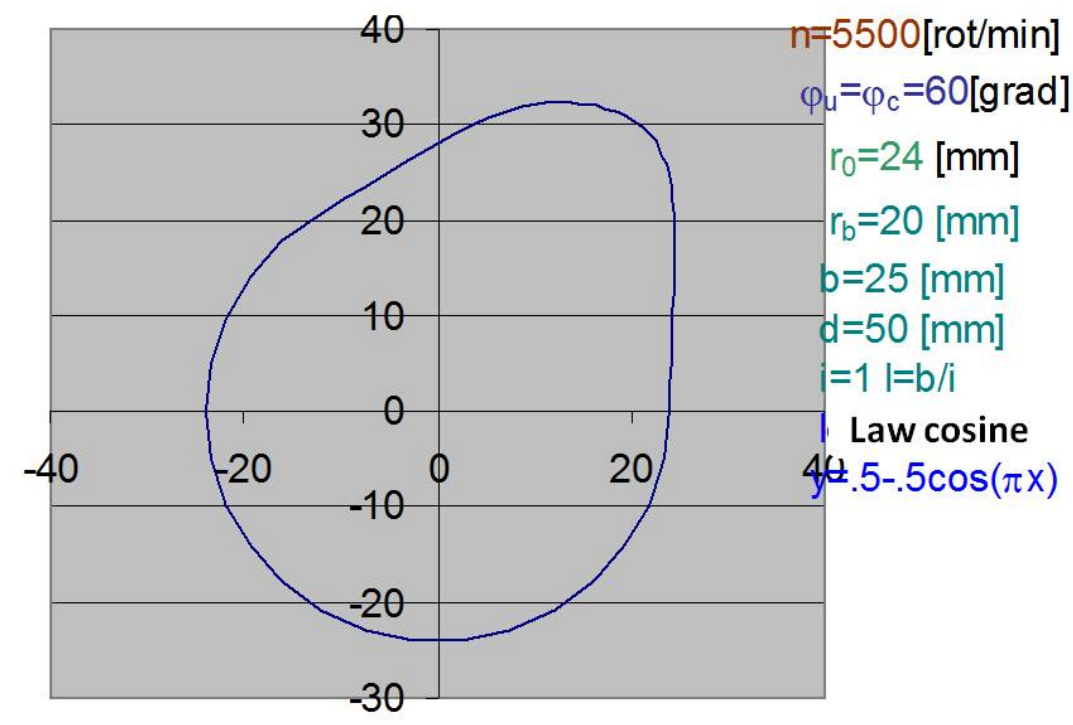

Figure 7: Cam profile of the module F. Law Sine, $\varphi_{u}=60$ [deg], $r_{0}=24[\mathrm{~mm}], r_{b}=20$ [mm].

In the Figure 8 one can see the dynamic analysis of the original law denominated by the authors C4P1-0, and in the Figure 9 the corresponding profile.

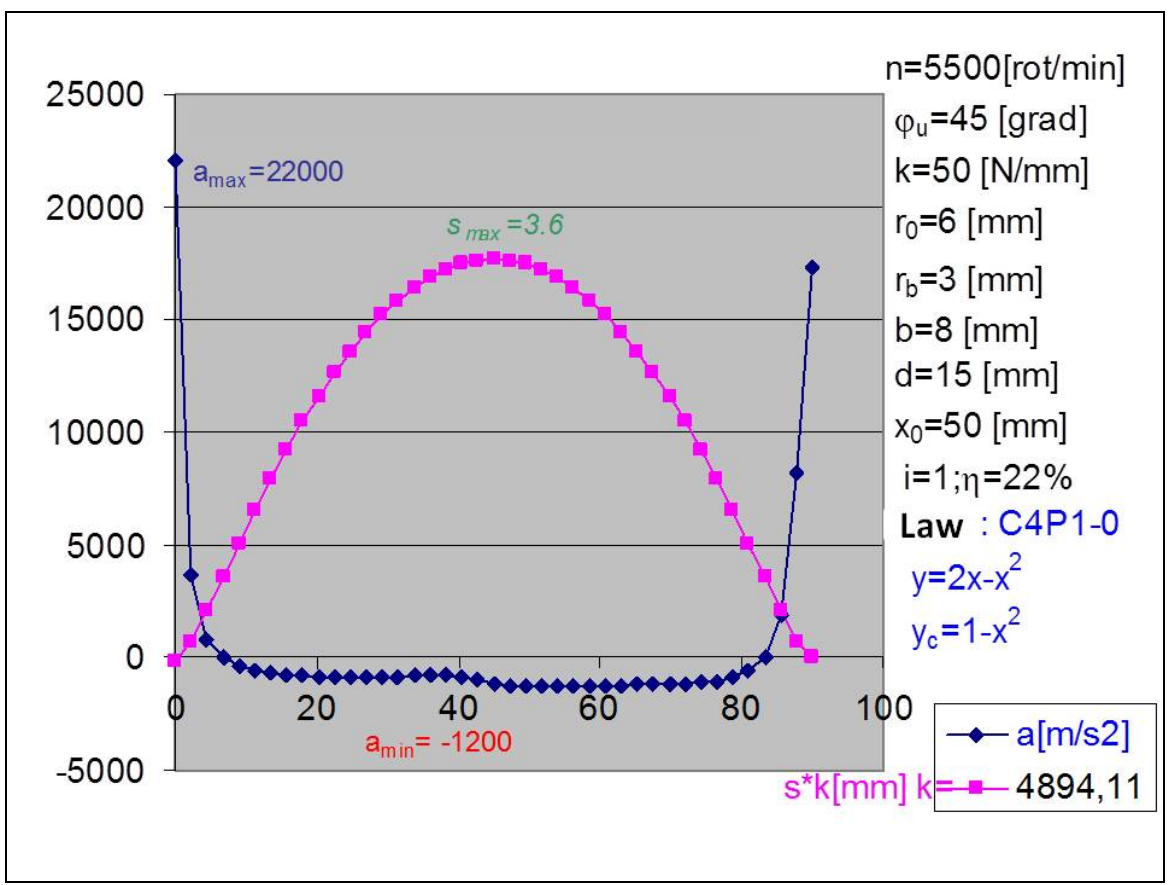

Figure 8: Dynamic analysis of the module F. Law C4P1-0, $\mathrm{n}=5500$ [rot $/ \mathrm{min}], \varphi u=45$ [deg], $r_{0}=6[\mathrm{~mm}], \mathrm{r}_{\mathrm{b}}=3[\mathrm{~mm}]$.

Opening of the valve is less, but the yield mechanism has increased. 


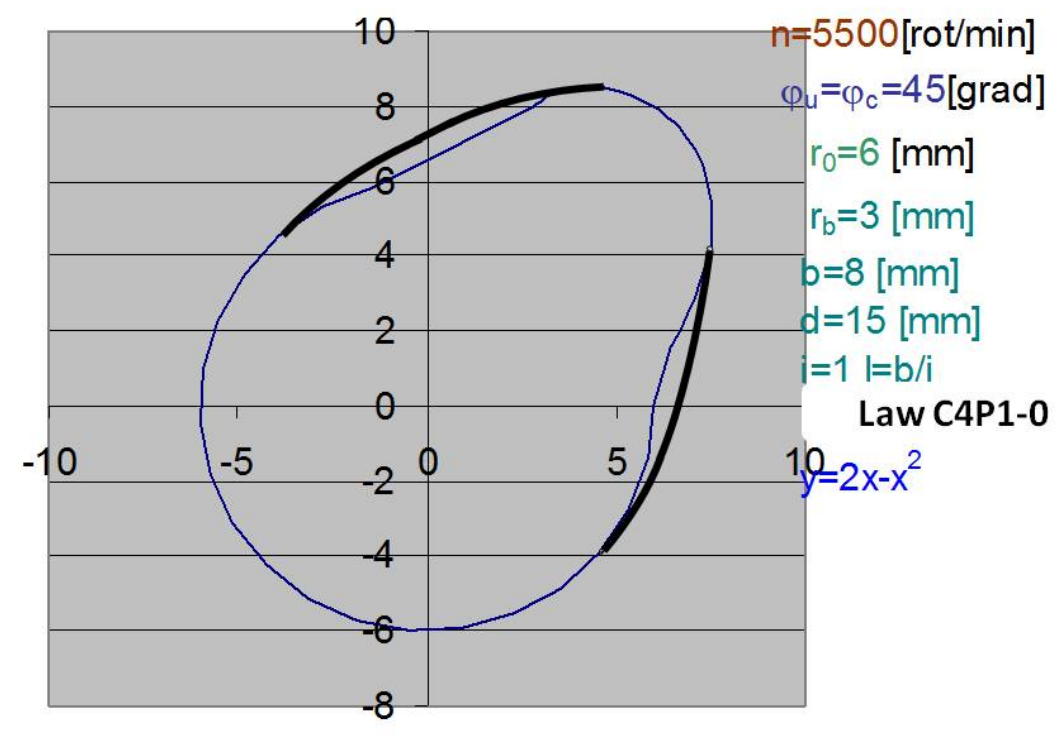

Figure 9: Cam profile of the module F. Law C4P1-0, $\varphi_{u}=45[\mathrm{deg}], \mathrm{r}_{0}=6[\mathrm{~mm}], \mathrm{r}_{b}=3$ $[\mathrm{mm}]$.

In the Figure 10 one can see the dynamic analysis of the original law denominated by the authors C4P3-2, and in the Figure 11 the corresponding profile.

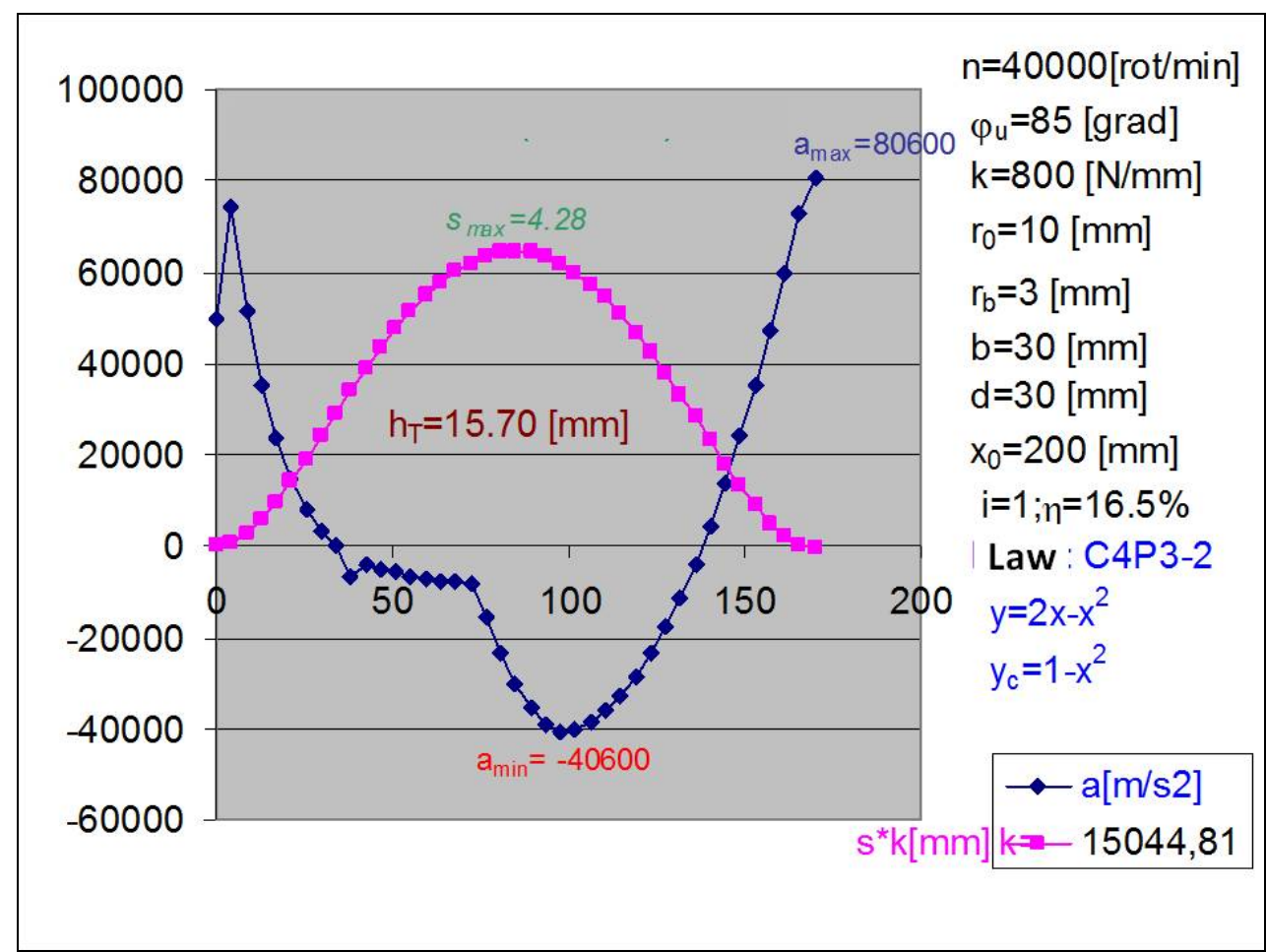

Figure 10: Dynamic analysis of the module F. Law C4P3-2, $\mathrm{n}=40000$ [rot $/ \mathrm{min}], \varphi_{u}=85$ [deg], $r_{0}=10[\mathrm{~mm}], \mathrm{r}_{b}=3[\mathrm{~mm}]$. 


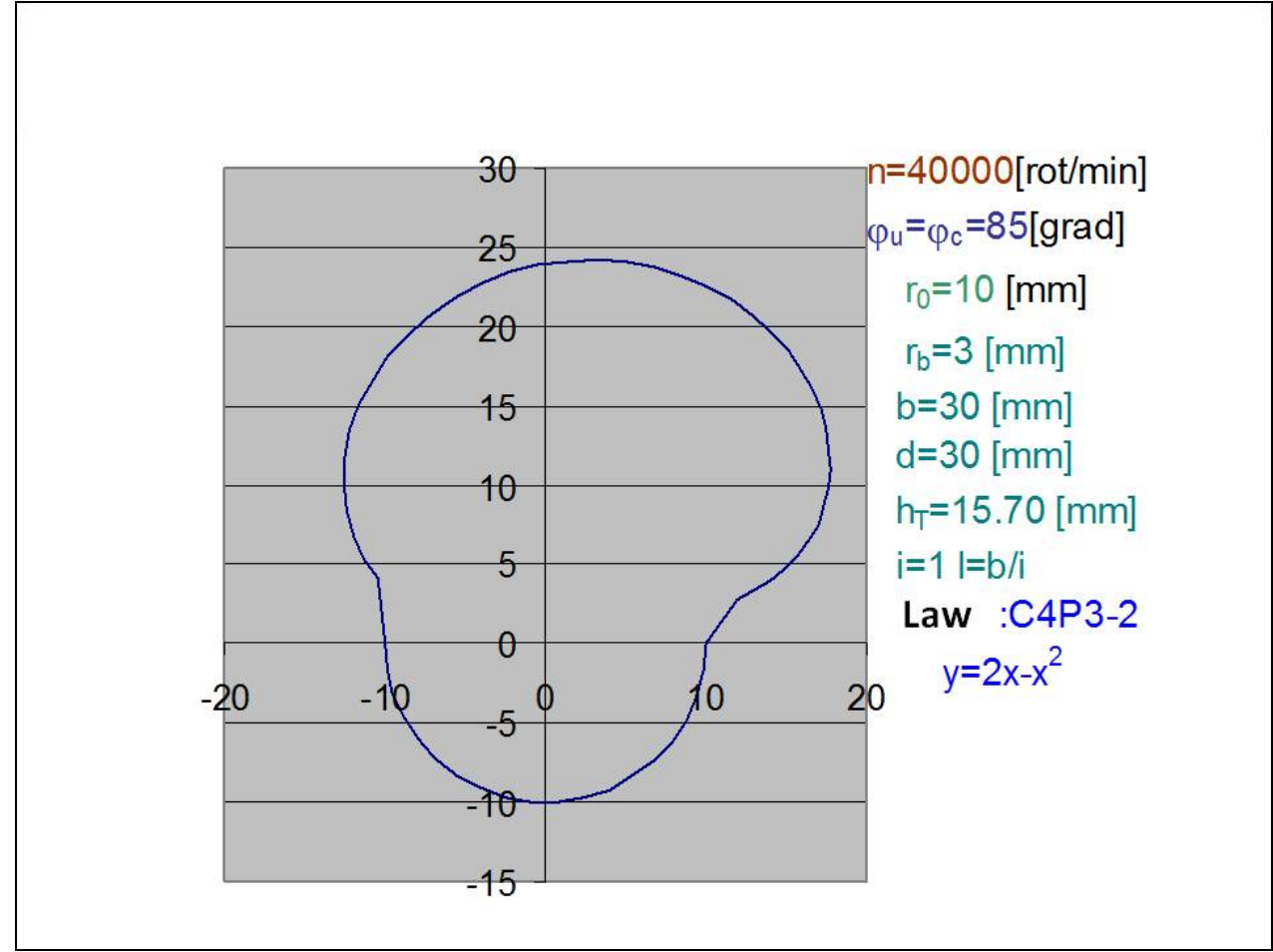

Figure 11: Cam profile of the module F. Law C4P3-2, $\varphi_{u}=85$ [deg], $r_{0}=10[\mathrm{~mm}], r_{b}=3$ $[\mathrm{mm}]$.

This last presented law, allow the increase of the drive shaft rotation speed to the $40000 \mathrm{rot} / \mathrm{min}$.

\section{DISCUSSION}

The distribution mechanisms work with small efficiency for about 150 years; this fact affects the total yield of the internal heat engines. Much of the mechanical energy of an engine is lost through the mechanism of distribution. Multi-years the yield of the distribution mechanisms was only $4-8 \%$.

In the past 20 years it has managed a lift up to the value of $14-18 \%$; car pollution has decreased and people have better breathing again.

The paper presents an original method to increase the efficiency of a mechanism with cam and follower, used at the distribution mechanisms.

This paper treats only module F: with rotary cam and rotating tappet with roller.

The distribution mechanism with rotation cam and rotating tappet with roll, allow us the increasing the rotation speed of the drive shaft and the increasing of the mechanical yield of the couple cam-tappet. 
This type of distribution mechanism allow and the construction of a compact motor (engine), which may work with high power producing a level of noxious gases lowest and a fuel consumption decreased as well.

Even the higher accelerations produced by these conditions may by increased by the valve spring adjustments.

These adjustments may be provided for some special dynamic calculation with an improved dynamic system, new created by authors.

The secret is appropriate increase in those two values: $k$ and $x_{0}$.

As long as we produce electricity and heat by burning fossil fuels is pointless to try to replace all thermal engines with electric motors, as loss of energy and pollution will be even larger.

However, it is well to continuously improve the thermal engines, to reduce thus fuel consumption.

At the heat engine with internal combustion a great loss of power is realized and by the distribution mechanism, reason for that we must try to improve the functionality of this mechanism.

\section{BENEFITS}

The main advantage is that the $\mathrm{F}$ module supports a much higher speed compared to classic module $C$ (An engine with high rotation speed can be more compact, more powerful and more economical, and without nuisance).

In addition at this mechanism (cam module F) and efficiency is higher.

\section{CONCLUSIONS}

At the heat engine with internal combustion a great loss of power is realized and by the distribution mechanism, reason for that to improve the functionality of this mechanism.

The dynamic synthesis of this type of distribution mechanism can be made shortly, by the Cartesian coordinates, but to determine these coordinates trigonometric parameters of the mechanism are necessary as well. The paper presents shortly an original trigonometric method to make the synthesis of a 
DOI: 10.14807/ijmp.v10i3.367

mechanism with rotary cam and rotated tappet with roll, used with priority at the distribution mechanisms from the heat engines with internal combustion.

This type of distribution can improve the changes of gases, and may decrease significantly the level of vibration, noises, and emissions.

The main advantage is that the $\mathrm{F}$ module supports a much higher speed compared to classic mode (An engine with high rotation speed can be more compact, more powerful and more economical, and without nuisance).

In addition at this mechanism (cam module F) and efficiency is higher.

\section{AUTHORS' CONTRIBUTION}

All the authors have contributed equally to carry out this work.

\section{REFERENCES}

AMORESANO, A.; AVAGLIANO, V.; NIOLA, V.; QUAREMBA, G. (2013) The Assessment of the in-Cylinder Pressure by Means of the Morpho-Dynamical Vibration Analysis - Methodology and Application, in IREME Journal, v. 7, n. 6, September, p. 999-1006.

CHOI, J. K.; KIM, S. C. (1994) HYUNDAI MOTOR CO. KOREA, An Experimental Study on the Frictional Characteristics in the Valve Train System. (945046), In FISITA CONGRESS, 17-21 October, Beijing, p. 374-380.

KARIKALAN, L.; CHANDRASEKARAN, M.; SUDHAGAR, K. (2013) Comparative Studies on Vegetable Oil Usage in $\mathrm{Cl}$ Engines as an Alternative to Diesel Fuel, in IREME Journal, v. 7, n. 4, p. 705-715.

PETRESCU, F. I.; PETRESCU, R. V. (2015a) Machine Motion Equations, Independent Journal of Management \& Production, v. 6, n. 3, p. 773-802.

PETRESCU, F. I. (2015b) Geometrical Synthesis of the Distribution Mechanisms, American Journal of Engineering and Applied Sciences, v. 8, n. 1, p. 63-81.

PETRESCU, F. I.; PETRESCU, R. V. (2014) Cam Gears Dynamics in the Classic Distribution, Independent Journal of Management \& Production, v. 5, n. 1, p. 166185.

PETRESCU, F. I.; PETRESCU, R. V. (2013) Dynamic Synthesis of the Rotary Cam and Translated Tappet with Roll, Engevista, v. 15, n. 3, p. 325-332.

WANG, W. (2011) Creation Design of Cam Mechanism Based on Reverse Engineering, Advanced Materials Research Journal, v. 230-232, p. 453-456. 